\title{
Development of Hydrocarbon Flow Calibration Facility as a National Standard*
}

\author{
Takashi SHIMADA**, Ryouji DOIHARA**, Yoshiya TERAO** \\ and Masaki TAKAMOTO** \\ ** National Institute of Advanced Industrial Science and Technology, \\ 1-1-1 Umezono, Tsukuba, Ibaraki, 305-8563 Japan \\ E-mail: t-shimada@ aist.go.jp
}

\begin{abstract}
A new primary standard for hydrocarbon flow measurements has been constructed at National Metrology Institute of Japan (NMIJ). The facility was designed for the calibration of hydrocarbon flowmeters in the flow rate range between 3 and $300 \mathrm{~m}^{3} / \mathrm{h}$. The expanded uncertainty is estimated to be $0.03 \%$ for volumetric flow rate and 0.02 $\%$ for mass flow rate (coverage factor: $k=2$ ). The primary standard is based on a static and gravimetric method with a flying start and finish. The facility consists of two test rigs using kerosene and light oil as working fluids. The test lines for the flowmeters are 50,100 and $150 \mathrm{~mm}$ in diameter and three servo positive displacement meters are used as working standards. To verify the calibration performance, a Coriolis flowmeter, a turbine meter and a positive displacement flowmeter have been calibrated at both test rigs. Furthermore, an international comparison with SP, Swedish National Testing Research Institute, was carried out. A screw-type positive displacement flowmeter was selected as the transfer standard and was calibrated at NMIJ and SP. The result shows that the two national standards at the two institutes agree within the quoted expanded uncertainties.
\end{abstract}

Key words : Flowmeter, Flow Measurement, Accuracy, Oil Meter, Calibration, Diverter, Uncertainty, Liquid Flow Rate

\section{Introduction}

Hydrocarbon flow measurements are of importance as a basis of taxes on and transactions of petroleum products, and in the field of product management for industrial petrochemical complexes. Since the uncertainty of oil flowmeters used for flow measurements is dependent on the properties of liquids, installation of the flowmeter, and the flow conditions, it is essential to calculate corrected values by comparing the standard flow rates and the reading of the flowmeter by flowing liquids into the flowmeter at standard flow rates and adjusting the flowmeter to the correct value indicated, to use the flowmeter for many kinds of hydrocarbons at high accuracy. Furthermore, it is necessary to periodically calibrate the flowmeter with liquids used to guarantee the performance of the flowmeter. Although a standard flow is composed of other standards, namely, mass, volume, density, temperature and so on, there had been no national standard for hydrocarbon flow measurements in Japan. As a result, flowmeter manufacturers and users are forced to be responsible for the calibration of flowmeters. However, it is essential to guarantee the consistency of flow measurements between nations with the globalization of economic activities and production. Accordingly, to comply with the requirement to set up a traceability certification system based on international standards, a national standard facility for hydrocarbon flow measurements is needed to enable the calibration of oil flowmeters.

Most calibration is carried out by a static and gravimetric method with a flying start and Japanese Original: Trans. Jpn. Soc. Mech. Eng., Vol.71, No.703, B (2005), pp.854-861 (Received 27 Aug., 2004) [DOI: 10.1299/jfst.2.23] 
because it is possible to calibrate flowmeters without changing the flow rate using a diverter system. However, the diverter, in which a free surface is formed, is rarely used for the calibration of hydrocarbon flowmeters, since hydrocarbons are flammable liquids. Therefore, in general, a flying method using a valve, typically including a piston prover and a ball prover, and a method of stopping the flow in the flowmeter are adopted for the calibration of hydrocarbon flowmeters.

In this study, kerosene and light oil test rigs are developed to calibrate flowmeters at high accuracy by a static and gravimetric method with a flying start and finish using a diverting system. The developed diverting system, using double wings ${ }^{(4)}$, was adopted in the calibration facility. Furthermore, the validity of the estimated uncertainty of the calibration for the flowmeters $^{(5)}$ (mass flow; $0.02 \%$, volumetric flow; $0.03 \%$ ) was experimentally investigated. Comparison experiments on the calibration of flowmeters were carried out using two kinds of weighing systems, which have different maximum weights, at the same test rig to investigate the agreement between K-factors at both systems. Moreover, a Coriolis flowmeter and a turbine meter were calibrated to verify the agreement of mass and volumetric flow rates between the kerosene and light oil test rigs. Finally, an international comparison with SP, Swedish National Testing Research Institute, was carried out using a screw-type positive displacement flowmeter.

\section{Outline of the Calibration Facility and Calibration Method}

\subsection{Outline of the calibration facility}

A schematic of the new primary standard for hydrocarbon flow measurements is shown in Fig. 1. Light oil and kerosene are used as the working liquids; each oil has a separate test line. The flow rate range is from 3 to $300 \mathrm{~m}^{3} / \mathrm{h}$. Although the kerosene and light oil test rigs are isolated, both test rigs cannot work simultaneously since a common chiller unit to control the liquid temperature is used. The calibration method adopted as the national standard for measuring hydrocarbon flow is a static and gravimetric method with a flying start and finish ${ }^{(6)}$ using a diverting system. In this method, liquid (kerosene or light oil) passing through the flowmeter via a nozzle of the diverter is collected in a weighing tank on a weighing scale for a given time, and then the standard mass flow rate is obtained by dividing the total mass of liquid, which is measured by the weighing scale, by the collection time. Furthermore, the volumetric flow rate is calculated by dividing the mass flow rate by the liquid density. The calibrations are carried out by comparison between the standard flow rates and those indicated by the calibrated flowmeter. As described in the above section, one of the characteristics of the calibration method using a diverter is the small changing flow during measurement in comparison with the flow-switching method using valves.

The test lines for the flowmeters under test are 50, 100 and $150 \mathrm{~mm}$ in diameter. The upstream straight pipe lengths for the flowmeters are more than 100 times greater than the pipe diameters $(15 \mathrm{~m})$ for each test line to generate an ideal velocity profile at the inlet of the flowmeter. During operation, three pumps of the same capacity are used to reduce the flow pulsation due to torque variation in the electric motor, while the other pumps remain at rest. In addition, when the working liquid flows into the weighing tank, the liquid in the 12 $\mathrm{m}^{3}$ buffer tank is transferred to the storage tank to keep the liquid level in the storage tank constant to reduce the fluctuation of the flow rate, so that the pressure at the suction side of the pumps remains unchanged. Fine mesh screens in the $43 \mathrm{~m}^{3}$ storage tanks and buffer tanks are effective for removing fine bubbles generated at the diverter section.

This facility is operational at temperatures from 15 to $35^{\circ} \mathrm{C}$. The temperature stability of working fluids has a large effect on the uncertainty of density, and hence, a sophisticated heat exchanger is installed in the test lines. Consequently, the fluctuation of temperature in the test line over 10 minutes is less than $\pm 0.03 \mathrm{~K}$.

Three servo positive displacement (PD) flowmeters are installed in the test rig as working standards and monitors of flow adjustment. These flowmeters of 50, 100, and $150 \mathrm{~mm}$ diame- 


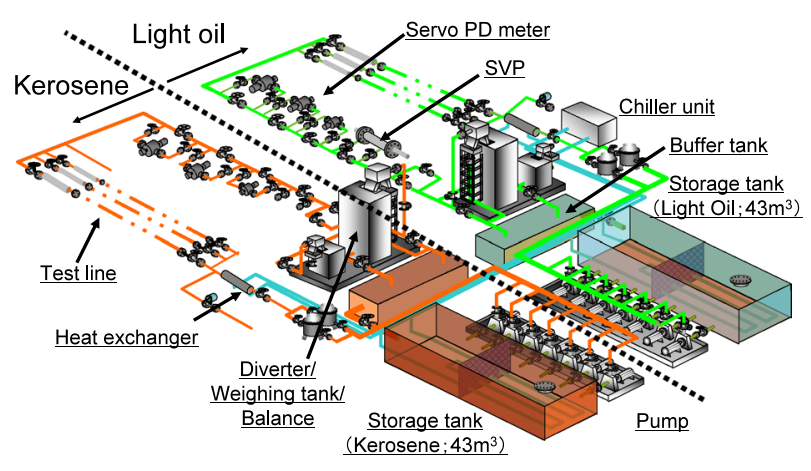

Fig. 1 Schematic of facility.

ter are set in the flow rate ranges from 3 to $30,7.5$ to 75 , and 30 to $300 \mathrm{~m}^{3} / \mathrm{h}$, respectively. The test meter and the servo PD meter are simultaneously calibrated using the primary standard, to confirm the reproducibility of the calibration system by checking the K-factor of the servo PD meter. The calibration uncertainty due to the low frequency of pulses outputted from the test meter is prevented from increasing by a pulse interpolation method.

The air conditioner must be an all-fresh-air system in accordance with fire laws, so that conditioned air at $20^{\circ} \mathrm{C}$ passes through the weighing room and the testing room and out to the atmosphere. The fluctuation of temperature in the weighing room affects the uncertainty of buoyancy correction for mass, and it is controlled to be less than $\pm 2 \mathrm{~K}$ daily. The temperature in the testing room is between $15{ }^{\circ} \mathrm{C}$ and $25^{\circ} \mathrm{C}$, and the humidity is controlled to be more than $30 \%$. Each test line has a large weighing tank with a $10 \mathrm{t}$ weighing scale and a small tank with a $1 \mathrm{t}$ weighing scale, one of which is selected depending on the flow rates. The $1 \mathrm{t}$ weighing scale is used when the flow rate is $3 \sim 30 \mathrm{~m}^{3} / \mathrm{h}$, and the $10 \mathrm{t}$ weighing scale is selected at $30 \sim 300 \mathrm{~m}^{3} / \mathrm{h}$. These weighing scales are equipped with standard dead weights, which are traceable to the national standard of mass of Japan. The $10 \mathrm{t}$ and $1 \mathrm{t}$ weighing scales have ten pieces of $1000 \mathrm{~kg}$ dead weight, and five pieces of $200 \mathrm{~kg}$ dead weight, respectively. These dead weights and an autoloading system enable the automatic calibration of the scales before and after the measurement, resulting in high reproducibility of the weight measurement. In addition, it is possible to automatically maintain a mass of 9,000 $10,000 \mathrm{~kg}$ or $800 \sim 1,000$ $\mathrm{kg}$ regardless of liquid level in the weighing tank when supplying oil, to avoid the impact of the falling liquid.

A new diverter system ${ }^{(4)}$ was adopted to divert the flow from the bypass to the weighing tank. This diverter has two wings that move at a constant speed in the same direction against the liquid jet, both at the beginning of measurement, when the flow is diverted to the weighing tank, and at the end of the measurement, when the flow is diverted to the bypass line, to cancel the effect of an asymmetric flow-velocity profile of the liquid jet flowing out of the rectangular nozzle. As a result, it was confirmed that the uncertainty of the collection time of liquid in the weighing tanks is negligible in comparison with the uncertainty of calibration for the flowmeters ${ }^{(5)}$. In addition, to prevent the vapor and mist of liquids caused by the free jet from entering the weighing tank room, the vapor and mist are exhausted outside the room by controlling the pressure in the diverter to be at a pressure slightly lower (about $10 \mathrm{~Pa}$ lower) than atmospheric pressure.

\subsection{Calibration procedure}

The data acquisition system of the facility is shown in Fig. 2. The flowmeters to be calibrated are restricted to the pulse-output type, which generate a pulse train at a frequency proportional to the flow rate. The calibration procedure of the primary standard is similar to that of the large water facility at $\mathrm{NMIJ}^{(2)}$. The calibration of the flowmeter is carried out by the following procedure.

( 1 ) Prepare flowmeter calibration, including installation of flowmeter under test and se- 


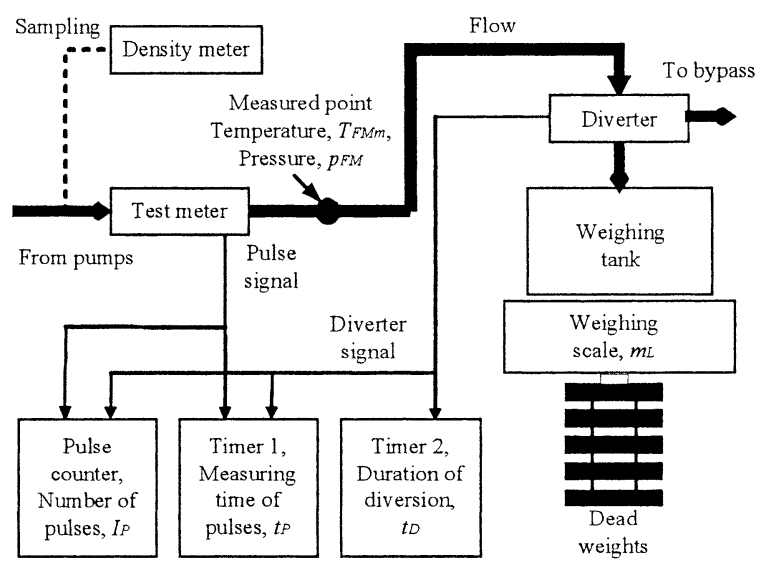

Fig. 2 Data acquisition system of the facility.

lect calibration conditions.

(2) Weighing scale selected is repetitively calibrated three times or more using weights. To calibrate a $10 \mathrm{t}$ weighing scale, loads of 8,9 and $10 \mathrm{t}$ are applied. To calibrate a $1 \mathrm{t}$ weighing scale, loads of 600, 800 and $1000 \mathrm{~kg}$ are applied.

( 3 ) Operate pumps to circulate working liquid and adjust flow rate, pressure and temperature as specified, and remove air in the line.

( 4 ) Sample working liquid. Measure its density three times or more at temperature controlled within $\pm 0.5 \mathrm{~K}$ of temperature set for the calibration work.

( 5 ) Collect working liquid in weighing tank using diverter when flow rate, temperature and pressure are stabilized. The diverter switch signal automatically starts up the pulse timer (Timer 1), the pulse counter, and the diversion timer (Timer 2).

(6) Switch flowing liquid to bypass line using diverter when the reading of weighing scale reaches the range of 9 to $10 \mathrm{t}$ or 900 to $1000 \mathrm{~kg}$ at the 10 or $1 \mathrm{t}$ weighing scale, respectively.

( 7 ) Diverter switch signal stops pulse timer.

( 8 ) Record weight reading after stabilization time (5 $\sim 7$ minutes). Discharge working liquid from weighing tank.

\subsection{Calculation of the calibration factor of the flowmeter (K-factor)}

When it is assumed that there is no leakage of oil and no generation of bubbles between the flowmeter under calibration and the nozzle of the diverter, the density of liquid in the flowmeter $\rho_{L F M}\left(\mathrm{~kg} / \mathrm{m}^{3}\right)$ and the volumetric flow $q_{F M}\left(\mathrm{~m}^{3} / \mathrm{s}\right)$ are described by Eq. (1) using the equation for the conservation of mass.

$$
\rho_{L F M} \cdot q_{F M}=\rho_{N Z} \cdot q_{N Z}+\frac{\partial\left(\rho_{D V} V_{D V}\right)}{\partial t}
$$

$\rho_{N Z}\left(\mathrm{~kg} / \mathrm{m}^{3}\right)$ and $q_{N Z}\left(\mathrm{~m}^{3} / \mathrm{s}\right)$ represent the density of the liquid and the volumetric flow discharged from the nozzle, respectively. $V_{D V}\left(\mathrm{~m}^{3}\right)$ and $\rho_{D V}\left(\mathrm{~kg} / \mathrm{m}^{3}\right)$ denote the volume and density, respectively, of the liquid within the connection pipe in the test rig between the flowmeter under test and the outlet of the diverter nozzle. Equation (2) is obtained by integrating Eq. (1) from the start of the measurement $t_{s}$ (s) to the end of the measurement $t_{f}(\mathrm{~s})$.

$$
\overline{Q_{F M}} \cdot t_{D}=M_{L}+\Delta M_{L D V}
$$

$\overline{Q_{F M}}(\mathrm{~kg} / \mathrm{s}), t_{D}(\mathrm{~s})$ and $M_{L}(\mathrm{~kg})$ represent the time-averaged mass flow rate through the flowmeter, the collection time $\left(=t_{f}-t_{s}\right)$ and the mass of the working liquid accumulated in the weighing tank, respectively. $\Delta M_{L D V}$ denotes the change in mass within the connection pipe during the collection time, and its expected value is estimated to be zero. Therefore, the mass 
flow rate $\overline{Q_{F M}}$ is obtained by Eq. (3).

$$
\overline{Q_{F M}}=\frac{M_{L}+\Delta M_{L D V}}{t_{D}} \approx \frac{M_{L}}{t_{D}}
$$

$\overline{Q_{F M}}$ is expressed by Eq. (4) using the time-averaged density $\overline{\rho_{L F M}}\left(\mathrm{~kg} / \mathrm{m}^{3}\right)$ in the flowmeter during collection, the time-averaged volumetric flow rate $\overline{q_{F M}}\left(\mathrm{~m}^{3} / \mathrm{s}\right)$, and the error $\Delta\left(\rho_{L F M} q_{F M}\right)(\mathrm{kg} / \mathrm{s})$ correlated between the flow rate and the density in the flowmeter.

$$
\overline{Q_{F M}}=\overline{\rho_{L F M}} \cdot \overline{q_{F M}}+\Delta\left(\rho_{L F M} q_{F M}\right)
$$

The expected value of $\Delta\left(\rho_{L F M} q_{F M}\right)$ is estimated to be zero; thus, the time-averaged volumetric flow rate through the flowmeter is obtained using Eq. (5).

$$
\overline{q_{F M}}=\frac{M_{L}+\Delta M_{L D V}}{\overline{\rho_{L F M}} \cdot t_{D}}-\frac{\Delta\left(\rho_{L F M} q_{F M}\right)}{\overline{\rho_{L F M}}} \approx \frac{M_{L}}{\overline{\rho_{L F M}} \cdot t_{D}}
$$

The weighing scales used to measure the mass of the liquid are calibrated using the dead weights. The mass $M_{D}(\mathrm{~kg})$ of the dead weights can be expressed by Eq. (6) in terms of conventional mass ${ }^{(7)} M_{S}(\mathrm{~kg})$.

$$
M_{D}=M_{S} \frac{(1-1.2 / 8000)}{\left(1-1.2 / \rho_{D}\right)}
$$

The weighing scales are calibrated using the dead weights in ambient air at a density of $\rho_{G C A L}\left(\mathrm{~kg} / \mathrm{m}^{3}\right)$. On the basis of reading $m_{C A L}(\mathrm{~kg})$ from the weighing scale loaded with $M_{D}$, a correction factor $k_{S}(-)$ of the weighing scale can be obtained using Eq. (7). The density $\rho_{D}$ of the dead weights is assumed to be $8000 \mathrm{~kg} / \mathrm{m}^{3}$, although it was estimated to be $8050 \mathrm{~kg} / \mathrm{m}^{3}$ from the design document. The expected value due to the effect $\delta k\left(\rho_{D}\right)(-)$ of the deviation of the density of the dead weights on the correction factor is estimated to be zero by adding the uncertainty due to the deviation.

$$
k_{S}=\frac{M_{D}}{m_{C A L}}\left(1-\rho_{G C A L} / \rho_{D}\right)=\frac{M_{S}}{m_{C A L}}\left(1-\frac{\rho_{G C A L}}{8000}\right)+\delta k\left(\rho_{D}\right) \approx \frac{M_{S}}{m_{C A L}}\left(1-\frac{\rho_{G C A L}}{8000}\right)
$$

To improve the accuracy (nonlinearity) characteristics of the weighing scale, linear interpolation between the correction factor $k_{M S 9}(-)$ when nine of the weights $M_{S 9}(\mathrm{~kg})$ with a nominal value of $1000 \mathrm{~kg}$ each are loaded and $k_{M S 10}(-)$ for ten of the weights $M_{S 10}(\mathrm{~kg})$ is used to calculate the correction factor $k_{m L}(-)$ for the $10 \mathrm{t}$ weighing system, when $9 \sim 10$ $\mathrm{t}$ of liquid has accumulated in the weighing tank. Therefore, the correction factor $k_{m L}$ of the weighing scale, which corresponds to the reading $m_{L}(\mathrm{~kg})$ from the weighing scale, is obtained using Eq. (8).

$$
k_{m L}=\frac{k_{M S 10}-k_{M S 9}}{M_{S 10}-M_{S 9}}\left(m_{L}-M_{S 9}\right)+k_{M S 9}
$$

When the $1 \mathrm{t}$ weighing scale is used, 900 to $1000 \mathrm{~kg}$ of working liquid has accumulated in the weighing tank. By performing linear interpolation against the correction factors of 800 and $1000 \mathrm{~kg}$, the correction factor of the $1 \mathrm{t}$ weighing scale can be obtained in the same manner as in the case of the $10 \mathrm{t}$ weighing scale.

The air density $\rho_{G m}\left(\mathrm{~kg} / \mathrm{m}^{3}\right)$ in term of room temperature $T_{\text {atm }}\left({ }^{\circ} \mathrm{C}\right)$ and atmospheric pressure $p_{\text {atm }}(\mathrm{kPa})$ is expressed by Eq. $(9)^{(8)}$.

$$
\rho_{G m}=\frac{1.2932}{1+\left(0.00367 T_{a t m}\right)}\left(\frac{p_{a t m}}{101.325}-H\right)
$$

Since the temperature in the weighing tank room is controlled at 15 to $25{ }^{\circ} \mathrm{C}$, saturated water vapor pressure varies from 1.7 to $3.2 \mathrm{kPa}^{(8)}$. The coefficient $H$, which represents the effect 
of the saturated water vapor pressure, is estimated to be $0 \sim 0.012$. For simplification, the median of coefficient $H$, which is 0.006 , is adopted in this research.

Oil that is discharged from the nozzle but not accumulated in the weighing tank due to mist and evaporation exhausted from the diverter to outside and remaining oil on the inside wall of the connecting duct result in a different mass. However, the expected value of this different mass of the liquid $\Delta M(\mathrm{~kg})$ is estimated to be zero. The mass of accumulated liquid $M_{L}$, therefore, can be obtained using Eq. (10), in terms of air density $\rho_{G m}$, density $\rho_{L W}\left(\mathrm{~kg} / \mathrm{m}^{3}\right)$ of the working liquid in the weighing tank and the reading $m_{L}$ of the weighing scale.

$$
M_{L}=\frac{k_{m L} \cdot m_{L}}{\left(1-\rho_{G m} / \rho_{L W}\right)}+\Delta M \approx \frac{k_{m L} \cdot m_{L}}{\left(1-\rho_{G m} / \rho_{L W}\right)}
$$

The working liquid is sampled at a piping system that branches out from the test line. Its density $\rho_{L R E F}\left(\mathrm{~kg} / \mathrm{m}^{3}\right)$ is measured using a density meter at temperature $T_{R E F}\left({ }^{\circ} \mathrm{C}\right)$ under atmospheric pressure. The density $\rho_{L W}$ of the working liquid in the weighing tank is obtained by Eq. (11) using temperature $T_{F M}\left({ }^{\circ} \mathrm{C}\right)$ measured with a thermometer mounted downstream of the flowmeter.

$$
\rho_{L W}=\rho_{L R E F}+\alpha_{L}\left(T_{F M}-T_{R E F}\right)
$$

The density $\overline{\rho_{L F M}}$ of the working liquid in the flowmeter under test is obtained using Eq. (12), by which the measured value is corrected using the temperature and pressure.

$$
\overline{\rho_{L F M}}=\left\{\rho_{L R E F}+\alpha_{L}\left(T_{F M}-T_{R E F}\right)\right\}\left(1+F_{L} p_{F M}\right)
$$

The pressure $p_{F M}$ in the flowmeter is obtained by averaging the pressure measured using a pressure gauge mounted upstream of the flowmeter under test and that measured using a pressure gauge mounted downstream of the flowmeter.

The thermal expansion coefficients $\alpha_{L}\left(\mathrm{~kg} \mathrm{~m}^{-3} \mathrm{~K}^{-1}\right)$ of the working liquids, that is, the sensitivity coefficients of density against temperature, are almost constant in the temperature range of 15 to $35^{\circ} \mathrm{C}$ by measurement using the density meter. Therefore, $\alpha_{L}$ is obtained using Eq. (13) in terms of temperature $T_{35}$ and density $\rho_{L 35}$ measured at $35^{\circ} \mathrm{C}$ and temperature $T_{15}$ and density $\rho_{L 15}$ measured at $15^{\circ} \mathrm{C}$.

$$
\alpha_{L}=\frac{\left(\rho_{L 35}-\rho_{L 15}\right)}{T_{35}-T_{15}}
$$

The calculation method for the compressibility factors $F_{L}\left(\mathrm{MPa}^{-1}\right)$ of the working liquids, that is, the sensitivity coefficients of density against pressure, is adopted by this equation ${ }^{(9)}$ converted from the density of the working liquids at $15^{\circ} \mathrm{C}$ and the temperature.

The pulse frequency of the flowmeter under test $f_{P}$ (pulse/s) is obtained using Eq. (14), in terms of the time interval $t_{P}(\mathrm{~s})$ from the rise of pulses at the flowmeter immediately after the signal of the diverter is generated at the beginning of measurement to the rise of pulses at the flowmeter immediately after the signal of the the diverter generated at the end of measurement, and the number of pulses $I_{P}$ (pulse) counted by the pulse counter during the time interval $t_{P}$.

$$
f_{P}=\frac{I_{P}}{t_{P}}
$$

Therefore, the calibration factor, that is, the K-factor for a volumetric flowmeter, $K_{f}$ (pulse $/ \mathrm{m}^{3}$ ) is described by Eq. (15) from Eqs. (5) and (14). Furthermore, the K-factor for a mass flowmeter $K_{f m}$ (pulse/kg) is described by Eq. (16) from Eqs. (3) and (14).

$$
\begin{gathered}
K_{f}=\frac{f_{P}}{\overline{q_{F M}}}=I_{P} \frac{t_{D}}{t_{P}} \frac{\overline{\rho_{L F M}}}{M_{L}} \\
K_{f m}=\frac{f_{P}}{\overline{Q_{F M}}}=\frac{I_{P}}{M_{L}} \frac{t_{D}}{t_{P}}
\end{gathered}
$$


Table 1 Liquid properties at NMIJ

\begin{tabular}{c|c|c|c|c}
\hline Liquid & \multicolumn{2}{|c|}{ Kerosene } & \multicolumn{2}{c}{ Light oil } \\
\hline Temperature $\left({ }^{\circ} \mathrm{C}\right)$ & 20 & 30 & 20 & 30 \\
Kinematic Viscosity $\left(\times 10^{-6} \mathrm{~m}^{2} / \mathrm{s}\right)$ & 1.7 & 1.5 & 6.8 & 5.2 \\
Density $\left(\mathrm{kg} / \mathrm{m}^{3}\right)$ & 790 & 785 & 830 & 825 \\
\hline
\end{tabular}

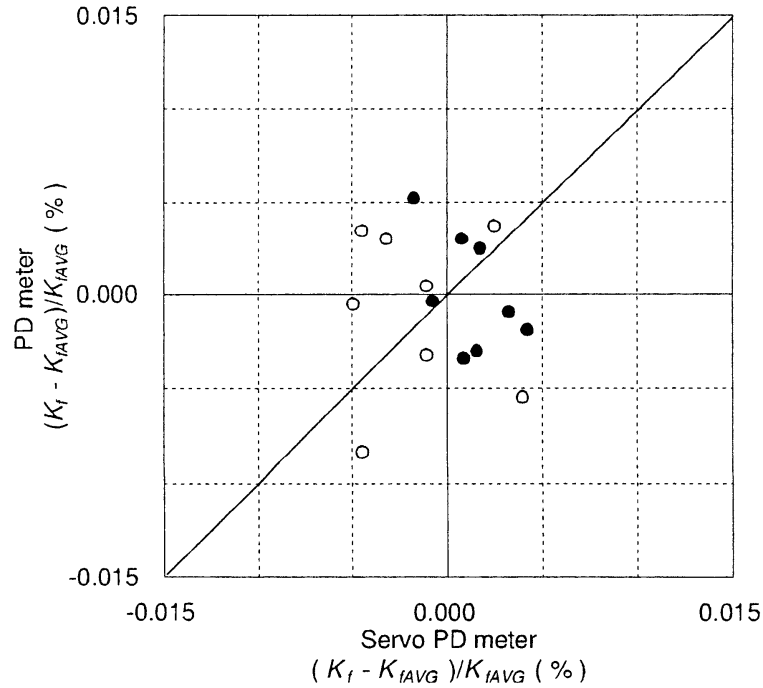

Fig. 3 K-factors obtained using the 10 and $1 \mathrm{t}$ weighing systems at the light oil test rig. The flow rate was $30 \mathrm{~m}^{3} / \mathrm{h}$. Each marker represents a result from a single diversion. $\bullet, 10 \mathrm{t} ; \bigcirc, 1 \mathrm{t}$.

\section{Verification of Uncertainty Analysis by Experiments}

The calibration factor, that is, the K-factor, is obtained by the calibration method described in the previous section. The expanded uncertainty of the mass flow rate $U\left(K_{f m}\right)$ (coverage factor $k=2$ ) and the expanded uncertainty of the volumetric flow rate $U\left(K_{f}\right)$ are analytically and experimentally estimated using Eqs. (17) and (18), respectively ${ }^{(5)}$.

$$
\begin{aligned}
& \frac{U\left(K_{f m}\right)}{\left|K_{f m}\right|}=0.02(\%) \\
& \frac{U\left(K_{f}\right)}{\left|K_{f}\right|}=0.03(\%)
\end{aligned}
$$

Accordingly, several types of flowmeters were calibrated to experimentally confirm the validity of this uncertainty analysis.

\subsection{Comparison of K-factors for different weighing systems at the same test rig}

The 10 or $1 \mathrm{t}$ weighing system is selected depending on the flow rate at the calibration of flowmeters for the primary standard for hydrocarbon flow. To investigate the agreement between K-factors obtained using 10 and $1 \mathrm{t}$ weighing systems at the same test rig, the servo PD meter (maximum flow rate: $75 \mathrm{~m}^{3} / \mathrm{h}$ ) and a turbine flowmeter (maximum flow rate: $72 \mathrm{~m}^{3} / \mathrm{h}$ ) were simultaneously calibrated at the kerosene test rig. Furthermore, a PD meter (maximum flow rate: $150 \mathrm{~m}^{3} / \mathrm{h}$ ) was used as a test meter at the light oil test rig. The calibrated flow rate was set to be $30 \mathrm{~m}^{3} / \mathrm{h}$, at which calibration can be carried out using both weighing systems, and the temperature of the liquid was $20^{\circ} \mathrm{C}$. The density and viscosity of the liquid are shown in Table 1.

The relative K-factors obtained using the PD meter at the light oil test rig against the averaged value $K_{f A V G}$ are plotted against the simultaneously calibrated K-factors of the servo PD meter in Fig. 3. Plots such as that shown in Fig. 3 are referred to as Youden plots. When 


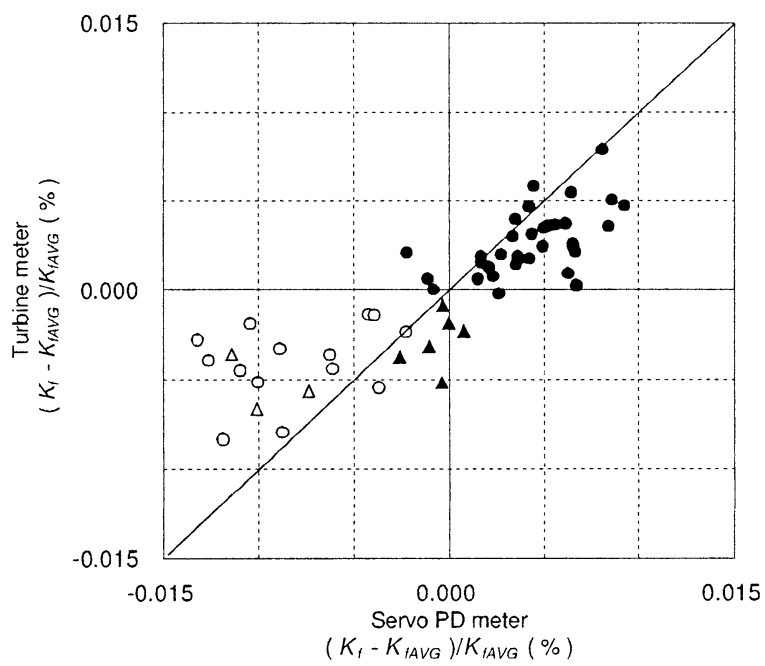

Fig. 4 Results for the 10 and $1 \mathrm{t}$ weighing systems at the kerosene test rig. The flowrate was $30 \mathrm{~m}^{3} / \mathrm{h}$. $\bullet, 10 \mathrm{t} ; \bigcirc, 1 \mathrm{t} ; \boldsymbol{\Lambda}, 10 \mathrm{t}$ without exhaust $\triangle, 1 \mathrm{t}$ without exhaust.

Table 2 Mean relative differences of $\mathrm{K}$-factors obtained using the $1 \mathrm{t}$ weighing system with exhaust at the kerosene test rig. The flow rate was $30 \mathrm{~m}^{3} / \mathrm{h}$.

\begin{tabular}{ccc}
\hline & Servo PD meter & Turbine meter \\
\hline $10 \mathrm{t}$ with exhaust $(\bullet)-1 \mathrm{t}$ with exhaust $(\bigcirc)$ & $0.012 \%$ & $0.007 \%$ \\
$10 \mathrm{t}$ without exhaust $(\mathbf{\Delta})-1 \mathrm{t}$ with exhaust $(\bigcirc)$ & $0.008 \%$ & $0.001 \%$ \\
$1 \mathrm{t}$ without exhaust $(\triangle)-1 \mathrm{t}$ with exhaust $(\bigcirc)$ & $-0.002 \%$ & $-0.001 \%$ \\
\hline
\end{tabular}

both simultaneously calibrated values have a positive correlation, namely, data lies in the first and third quadrants in the Cartesian coordinate system, the deviations of the K-factors are caused by the calibration facility. On the other hand, if the correlation of calibrated values does not appear, the deviation of the K-factors is caused by a random effect due to the flowmeters or other inconsistencies ${ }^{(10)}$. Figure 3 indicates that the difference in $\mathrm{K}$-factor between the $10 \mathrm{t}$ weighing system and the $1 \mathrm{t}$ weighing system is small at the light oil test rig. Furthermore, the mean relative difference of K-factors is $0.004 \%$ at the servo PD meter and less than 0.001 $\%$ at the PD meter. These values are very small in comparison with the expanded uncertainty, $0.03 \%(k=2)$, demonstrating that the effect of the difference of the weighing systems at the light oil test rig is negligible.

Figure 4 shows, as Youden plots, the results obtained using the servo PD meter and the turbine meter at the kerosene test rig. The systematic deviations between the K-factors at the $10 \mathrm{t}$ weighing system and those at the $1 \mathrm{t}$ weighing system are shown in Fig. 4 . The averaged K-factors obtained using the servo PD meter and the turbine meter using the $10 \mathrm{t}$ weighing system are $0.012 \%$ and $0.007 \%$, which are higher than those obtained using the 1 $\mathrm{t}$ weighing system. Furthermore, a positive correlation between both $\mathrm{K}$-factors indicates that this difference is caused by the difference in the standard flow rate due to the two weighing systems of the calibration facility. This difference was predicted to be caused by the exhaust system, which prevents vapor and mist from flowing from the diverter to the weighing room. Calibration was also carried out under a vapor-rich condition without the exhaust system to investigate the loss of liquid due to the exhaust system. These results are also shown in Fig. 4. The mean relative differences of $\mathrm{K}$-factors obtained using the $1 \mathrm{t}$ weighing system with the exhaust at the kerosene test rig are listed in Table 2. The average K-factor ( $\mathbf{\Delta})$ of both flowmeters, obtained using the $10 \mathrm{t}$ weighing system under the vapor-rich condition without the exhaust system, is approximately $0.005 \%$ lower than that $(\bullet)$ of the normal calibration, and the maximum decreased value is $0.012 \%$. The same experiment was carried out at a different flow rate. The decreased value was less than $0.003 \%$ at $60 \mathrm{~m}^{3} / \mathrm{h}$, and less than 0.002 $\%$ at $90 \mathrm{~m}^{3} / \mathrm{h}$. Therefore, the deviation decreased as flow rate increased, indicating that vapor 


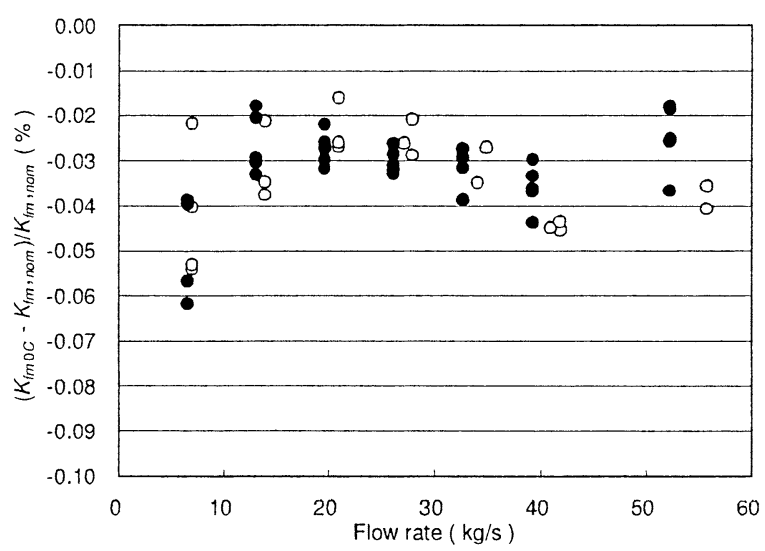

Fig. 5 Corrected K-factors of Coriolis meter. Each marker represents a result from a single diversion. $\bullet$, kerosene ; $\bigcirc$, light oil.

and mist from the diverter is exhausted at a constant rate $(\mathrm{kg} / \mathrm{s})$. In contrast, as Table 2 shows, the difference for the $1 \mathrm{t}$ weighing system is less than $0.002 \%$, indicating that the effect of liquid loss is negligible. Furthermore, the effect of the exhaust system was also experimentally estimated to be negligible at the light oil test rig.

On the other hand, although the difference between the K-factor of the turbine meter at the $10 \mathrm{t}$ weighing system without the exhaust $(\mathbf{\Delta})$ and that at the $1 \mathrm{t}$ weighing system $(\triangle)$ is less than $0.003 \%$, the value obtained using the servo PD meter is $0.010 \%$. One of the reasons for this is considered to be the interaction of the fluctuation of flow between the flowmeters and the test rig; however, this requires further investigation.

Consequently, it is clear that the difference of $\mathrm{K}$-factors for different weighing systems at the kerosene test rig is mainly caused by the exhaust of vapor in the $10 \mathrm{t}$ diverter.

\subsection{Comparison of $\mathrm{K}$-factors for the different test rigs}

A Coriolis flowmeter, namely, a mass flowmeter, was calibrated to verify the agreement of mass flow rate between the two test rigs using kerosene and light oil. This comparison test for the different test rigs was carried out using the mass flowmeter, whose maximum flow rate is $75 \mathrm{~kg} / \mathrm{s}$. The liquid temperature was $20^{\circ} \mathrm{C}$ and the flow rate range was $6.5 \sim 55$ $\mathrm{kg} / \mathrm{s}\left(30 \sim 240 \mathrm{~m}^{3} / \mathrm{h}\right)$. In general, the performance of Coriolis flowmeters is hardly affected by liquid properties, that is, viscosity and density; however, it is affected by zero stability, pressure, installation conditions, pipe vibration, and other factors ${ }^{(11)}$. Therefore, the calibrated $\mathrm{K}$-factors were converted to the corrected K-factors $K_{f m 0}$ under atmospheric pressure using the pressure effect on K-factors that the manufacturer recommended, $F_{F M}=-0.09 \% / \mathrm{MPa}$. Although the zero was adjusted before calibration, since the flow rate reading $\Delta Q_{m 0}$ for a static working liquid after calibration was measured to be $\pm 20 \mathrm{~kg} / \mathrm{h}, \Delta Q_{m 0}$ was assumed to be the zero value of the meter during measurement. Then, the K-factor $K_{f m 0 C}$ corrected by the effect of zero stability is obtained using Eq. (19) and the pressure $p_{F M}$ at the flowmeter.

$$
K_{f m 0 C}=K_{f m}\left(1-F_{F M} p_{F M}\right)\left(1-\frac{\Delta Q_{m 0}}{\overline{Q_{F M}}}\right)
$$

The relative corrected K-factors of the Coriolis flowmeter against the nominal K-factor $K_{f m, n o m}$ (100 pulse/kg) are shown in Fig. 5. As Fig. 5 shows, the agreement between the corrected Kfactors of both test rigs was within $\pm 0.02 \%$, which indicates that the expanded uncertainty of mass flow estimated analytically to be $0.02 \%(k=2)$ is adequate. Furthermore, the Coriolis flowmeter has a possibility to measure the mass flow rate without being affected by the liquid properties by appropriate correction of the effects of zero stability and pressure.

The turbine meter, whose K-factor is dependent on the Re number ${ }^{(12)-(14)}$, was calibrated at both test rigs to verify the calibration performance of the volumetric flow rate. The tem- 


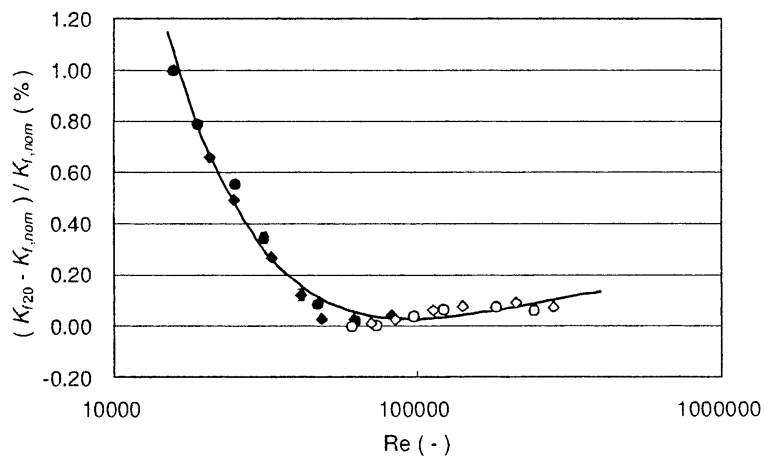

Fig. 6 Corrected K-factors of turbine meter. $\bigcirc$, light oil at $20^{\circ} \mathrm{C}$; $\diamond$, light oil at $30^{\circ} \mathrm{C}$ ; $\bullet$, kerosene at $20^{\circ} \mathrm{C} ; \diamond$, kerosene at $30^{\circ} \mathrm{C}$. The solid line indicates Eq. (21). Each marker represents an average of more than five measurements.

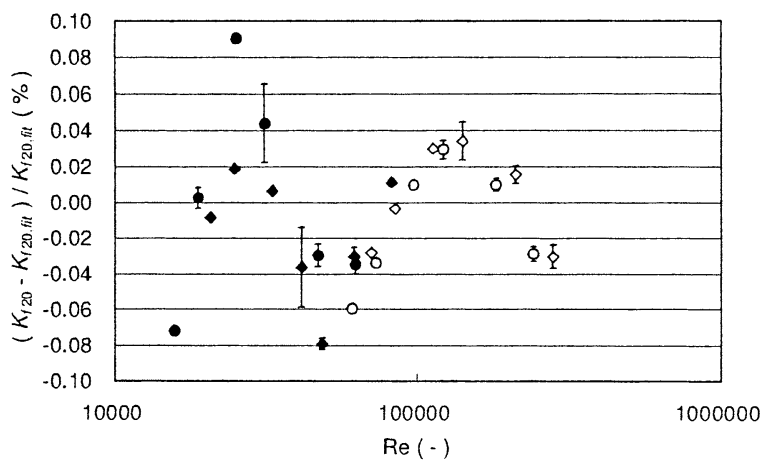

Fig. 7 Differences of K-factors from the fitting curve. The symbols are the same as in Fig. 6.

peratures of the working liquid were 20 and $30{ }^{\circ} \mathrm{C}$ to enable the change in viscosity, and the calibrated flow rate was $15 \sim 60 \mathrm{~m}^{3} / \mathrm{h}$. Therefore, the corrected $\mathrm{K}$-factor $K_{f 20}$ at $20{ }^{\circ} \mathrm{C}$ was calculated using Eq. (20) on the basis of the thermal expansion coefficient of the material of the flowmeter $\alpha_{S U S}$ (stainless steel ; $\left.0.0136 \% / \mathrm{MPa}\right)^{(12)}$.

$$
K_{f 20}=K_{f}\left(1+3 \alpha_{S U S}\left(T_{F M}-20\right)\right)
$$

The mean and relative $\mathrm{K}$-factors corrected by temperature against the nominal $\mathrm{K}$-factor $K_{f, \text { nom }}$ (32.895 pulse/L) of the turbine meter are plotted against Re number in Fig. 6. The solid line in the figure indicates the fitting curve plotted against Re number $K_{f 20, f i t}$ described by Eq. (21), which was fitted by the least-squares method. Furthermore, the relative differences between the calibrated K-factors $k_{f 20}$ and the fitted values are shown in Fig. 7.

$$
K_{f 20, f i t}=33.077+\frac{1.5459 \times 10^{4}}{\operatorname{Re}}-\frac{1.0238 \times 10^{2}}{\operatorname{Re}^{0.5}}-3.6322 \times 10^{-8} \operatorname{Re}
$$

Figure 7 shows that it is possible to fit the K-factors in the calibrated Re range within \pm 0.1 $\%$, and the differences of K-factors due to the different test rigs are less than $\pm 0.03 \%$. These results indicate that the $\mathrm{K}$-factors for both test rigs agree within the expanded uncertainty of the volumetric flow.

Consequently, it is obvious that the uncertainty due to the systematic effect caused by the two test rigs, which have different liquids, is within the expanded uncertainty of calibration.

\subsection{International comparison for verification}

To verify the agreement between the calibration values obtained by this facility and those at other national standard facilities, an international comparison with SP, Swedish National Testing Research Institute, was carried out. A screw-type positive displacement flowmeter 
Table 3 Experimental configuration for comparison between NMIJ and SP.

\begin{tabular}{c|c|c}
\hline & NMIJ & SP \\
\hline Liquid used & Light oil & Exxsol D120 \\
Kinematic viscosity $\left(20^{\circ} \mathrm{C}\right)$ & $6.8 \times 10^{-6} \mathrm{~m}^{2} / \mathrm{s}$ & $5.3 \times 10^{-6} \mathrm{~m}^{2} / \mathrm{s}$ \\
Density $\left(20^{\circ} \mathrm{C}\right)$ & $830 \mathrm{~kg} / \mathrm{m}^{3}$ & $820 \mathrm{~kg} / \mathrm{m}^{3}$ \\
Temperature & $19.91 \sim 20.06{ }^{\circ} \mathrm{C}$ & $19.46 \sim 21.42{ }^{\circ} \mathrm{C}$ \\
Test pressure & $0.28 \sim 0.44 \mathrm{MPa}$ & $0.20 \sim 0.28 \mathrm{MPa}$ \\
Flow rate & $30 \sim 300 \mathrm{~m}^{3} / \mathrm{h}$ & $30 \sim 300 \mathrm{~m}^{3} / \mathrm{h}$ \\
\hline
\end{tabular}

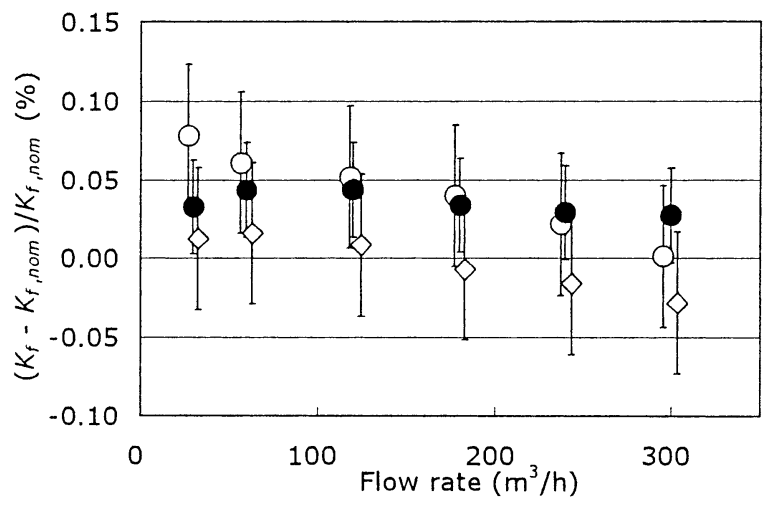

Fig. 8 Results of international comparison at NMIJ and SP for the screw meter. $\bigcirc$, SP $1 ; \bullet$, NMIJ ; $\diamond$, SP 2 . Each error bar indicates the expanded uncertainty of calibration.

whose maximum flow rate is $450 \mathrm{~m}^{3} / \mathrm{h}$ was selected as the transfer standard. This flowmeter was the same type as that used for intercomparison in Europe ${ }^{(14)}$. A flying method using a ball prover, whose volume is $4 \mathrm{~m}^{3}$, was adopted at the calibration facility in SP. The calibration uncertainty at SP was evaluated to be $\pm 0.045 \%$. The experimental conditions at both calibration facilities are shown in Table 3. All results are shown as mean values of $2 \sim 8$ individual test runs with a standard deviation of less than $0.01 \%$. The flowmeter was calibrated at SP and shipped to NMIJ. After calibration at NMIJ, it was returned to SP where it was calibrated again to confirm the reproducibility of the flowmeter and the transport effect.

Figure 8 shows results for the screw meter obtained at NMIJ and at SP. The calibration results obtained at SP changed by about $0.04 \%$ from the first measurement $(\mathrm{SP} 1 ; \bigcirc$ ) to the second measurement (SP 2; $)$ ). Although the reason for the deviation in results before and after shipping is not yet known, possible reasons are transport damage, wear, meter malfunction or errors in test equipment. On the other hand, relative differences between calibrated K-factors at SP 1 and those at NMIJ are within $0.05 \%$, and relative differences between SP 2 and NMIJ are within $0.06 \%$. Furthermore, En values, which are defined by Eq. (22) and represent the degree of agreement, were less than unity over the entire flow rate range.

$$
E n=\left|\frac{\left(K_{f, N M I J}-K_{f, S P}\right) / K_{f, n o m}}{\sqrt{U_{N M I J}^{2}+U_{S P}^{2}}}\right|
$$

$K_{f, N M I J}$ and $K_{f, S P}$ represent K-factors obtained at NMIJ and those obtained at SP, respectively. $U_{N M I J}$ and $U_{S P}$ denote the expanded uncertainty of calibration at NMIJ and that at SP, respectively. The fact that En values are less than unity indicates that the calibration at NMIJ agrees with that at SP within the quoted expanded uncertainties of calibration at the two institutes. Therefore, it is clear that the quoted uncertainty at this calibration facility for international comparison is reasonable.

\section{Conclusion}

In this study, a new hydrocarbon flow calibration facility, which can calibrate oil flowmeters at high accuracy, was reported, and the validity of the uncertainty for calibration was in- 
vestigated experimentally using the flowmeters. As a result, the calibrated values at different test rigs agree within the uncertainty, confirming the consistency of calibration. Furthermore, it is clear that the quoted uncertainty for calibration $(0.03 \%)$ is acceptable for international comparison with other national standards.

\section{Acknowledgements}

The authors gratefully acknowledge helpful support with international comparison from Mr. Krister Stolt and Mr. Anders Anderson, Swedish National Testing and Research Institute.

\section{References}

( 1 ) Japan Measuring Instruments Federation ed., Flowmeters Handbook (in Japanese), (2005), pp. 17-22.

( 2 ) Terao, Y. and Takamoto, M., Uncertainty Analysis of Large Water Flow Calibration Facility, Transactions of the Society of Instrument and Control Engineers, Vol. 36, No. 1, (2000), pp. 10-15.

( 3 ) Pöschel, W. and Engel, R., The Concept of a New Primary Standard for Liquid Flow Measurement at PTB Braunschweig, Proceedings of the 9th International Conference on Flow Measurement, (1998), pp. 7-12.

( 4 ) Shimada, T. et al., A Novel Diverter for Liquid Flow Calibration Facilities, Transactions of the Japan Society of Mechanical Engineers, Series B, Vol. 68, No. 665, (2002), pp. 137-143.

( 5 ) Shimada, T. et al., Uncertainty Analysis of Primary Standard for Hydrocarbon Flow at NMIJ, Proceedings of the 12th International Conference on Flow Measurement, (2004), pp. 208-213.

( 6 ) The International Organization for Standardization, Measurement of Liquid Flow in Closed Conduits - Weighing Methods, International Standard, ISO 4185-1980, 1st ed., (1980), pp. 1-21.

( 7 ) The International Organization for Legal Metrology, International Recommendation, Weights of Classes $E_{1}, E_{2}, F_{1}, F_{2}, M_{1}, M_{2}, M_{3}$, OIML R111, (1994), pp. 1-24.

( 8 ) The Chemical Society of Japan ed., Chemical Handbook (in Japanese), (2004), Maruzen.

( 9 ) American Petroleum Institute, Compressibility Factors for Hydrocarbons: 638 - 1074 Kilograms per Cubic Meter Range, Manual of Petroleum Measurement Standards Chapter 11.2.1M, (1984).

(10) Mattingly, G. E., Fluid Mechanics Measurement, edited by Goldstein, R. J., (1996), pp. 301-366, Taylor \& Francis.

(11) Paton, R. and Carlyle, E., Calibration techniques for Coriolis mass flowmeters, NEL Report 118/97, (1998).

(12) Japanese Standards Association, Method of Flow Measurement by Turbine Meters, JIS Z 8765-1980, (1980).

(13) Hutton, S. P., The Effect of Fluid Viscosity on Turbine Meter Calibration, Proceedings of the International Conference on Flow Measurement in the Mid-80', (1986), Paper 1.1

(14) Lau, P. and Stolt, K., Calibration Intercomparison on Flowmeters for Kerosene, SP Report 77, (1995). 